\title{
Thermocoagulation as a Surgical Approach for the Treatment of Obsessive-Compulsive Disorder in Refractory Patients: Systematic Review
}

\section{Termocoagulação como abordagem cirúrgica para o tratamento de transtorno obsessivo-compulsivo em pacientes refratários: revisão sistemática}

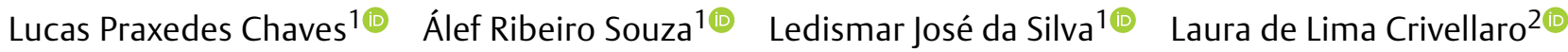 \\ Marina Ferreira da Silva ${ }^{2}$ \\ ${ }^{1}$ Escola de Ciências Médicas, Farmacêuticas e Biomédicas, Pontifícia \\ Universidade Católica de Goiás (PUC-Goiás), Goiânia, GO, Brazil \\ 2 Faculdade de Medicina, Universidade Católica de Brasília, DF, Brazil \\ Arq Bras Neurocir 2021;40(4):e333-e338. \\ Address for correspondence Ledismar José da Silva, MSc, \\ Escola de Ciências Médicas, Farmacêuticas e Biomédicas, Pontifícia \\ Universidade Católica de Goiás (PUC-Goiás), Avenida Universitária \\ 1.440, Setor Universitário, 74605-010, Goiânia, GO, Brazil \\ (e-mail: ledismarsilva@gmail.com).
}

\begin{abstract}
Keywords

- obsessive compulsive disorder

- refractory

- thermocoagulation

- neurosurgery

Obsessive-compulsive disorder (OCD), a disabling chronic neuropsychiatric disease, entails high economic costs to society and has high morbidity and mortality rates. The first-line treatments for $O C D$ are selective serotonin reuptake inhibitors and cognitivebehavioral therapy. However, this disorder has the highest refractory index to noninvasive treatment. Alternatively, ablative thermocoagulation neurosurgical techniques have shown efficacy and few adverse effects. The present systematic review aimed to identify validated protocols to observe the effectiveness of ablative procedures in the treatment of severe and refractory OCD, as well as their possible adverse effects and benefits. This review supports the effectiveness of ablative methods by presenting them as a safe non-experimental therapeutic option for cases of highlyrefractory OCD. Additional relevant findings were the improvement in cognitive function, functional capacity, affective orientation, and quality of life, which contribute to the destigmatization of this surgical technique. Further controlled studies may lead to the individualization of recommendations of targets for ablative thermocoagulation.
\end{abstract}

received

October 22, 2020

accepted

March 9, 2021

published online

August 30, 2021
DOI https://doi.org/ 10.1055/s-0041-1731013. ISSN $0103-5355$.

\footnotetext{
(c) 2021. Sociedade Brasileira de Neurocirurgia. All rights reserved. This is an open access article published by Thieme under the terms of the Creative Commons Attribution-NonDerivative-NonCommercial-License, permitting copying and reproduction so long as the original work is given appropriate credit. Contents may not be used for commercial purposes, or adapted, remixed, transformed or built upon. (https://creativecommons.org/ licenses/by-nc-nd/4.0/) Thieme Revinter Publicações Ltda., Rua do Matoso 170, Rio de Janeiro, RJ, CEP 20270-135, Brazil
} 


\section{Resumo}
Palavras-chave
- transtorno obsessivo- compulsivo
- refratário
- termocoagulação
- neurocirurgia

O transtorno obsessivo-compulsivo (TOC), uma doença neuropsiquiátrica crônica e incapacitante, acarreta altos custos econômicos para a sociedade e tem taxas altas de morbidade e mortalidade. Os tratamentos de primeira linha para TOC são inibidores seletivos de recaptação da serotonina e terapia cognitivo-comportamental. No entanto, esse transtorno apresenta o índice refratário mais alto ao tratamento não invasivo. Alternativamente, as técnicas neurocirúrgicas de termocoagulação ablativa têm demonstrado eficácia e poucos efeitos adversos. Esta revisão sistemática teve como objetivo identificar protocolos validados para a observação da eficácia dos procedimentos ablativos no tratamento de TOC grave e refratário, bem como seus possíveis efeitos adversos e benefícios. Esta revisão apoia a eficácia dos métodos ablativos, apresentando-os como uma opção terapêutica não experimental e segura para casos de TOC altamente refratários. Outros achados relevantes foram a melhora de função cognitiva, da capacidade funcional, da orientação afetiva, e da qualidade de vida, que contribuem para a desestigmatização dessa técnica cirúrgica. Outros estudos controlados podem levar à individualização das recomendações de alvos para termocoagulação ablativa.

\section{Introduction}

Obsessive-compulsive disorder (OCD) is a debilitating chronic neuropsychiatric disorder that is marked by distress and anxiety. The diagnosis is based on the presence of obsessions (recurrent and persistent thoughts, urges, behaviors, intrusive and unwanted images) and/or compulsions (repetitive behaviors or mental acts the individual feels driven to perform, following rigid rules, to reduce or neutralize the discomfort), which are strictly regulated, demand time from the person, cause impaired social behavior, and are not explained by the physiological effects of any substance in use or an existing medical condition. ${ }^{1-4}$

The symptoms of OCD usually start from the middle of the third to the early fourth decades of life, and the proportion of women affected is slightly higher than that of men. However, the adolescent-onset disease inverts this trend, and its prevalence is three times higher in males than in females. ${ }^{1,5}$

International multicentric studies suggest annual and lifetime prevalences ranging from $1.1 \%$ to $1.8 \%$ and from $1.9 \%$ to $2.5 \%$ respectively, ${ }^{5}$ making it the fourth most common psychiatric disorder in the world. ${ }^{1}$ It is estimated that 50 million people suffer from OCD worldwide. ${ }^{6}$

The disorder may be accompanied by other psychiatric syndromes such as generalized anxiety disorder and major depressive disorder. In addition, OCD has a high mortality rate, given that $10 \%$ to $27 \%$ of the people that have this illness attempt suicide at some point in life. It corresponds to the tenth cause of health-related absenteeism due to incapacity to work. This reduces the active workforce and increases the costs in the areas of social security and health. ${ }^{3}$

The annual costs of treatments for OCD in the United States reach $\sim 10.6$ billion dollars, but one third of this budget is not efficiently used. Additionally, $\sim 40$ billion dollars are annually invested by the American government in sickness insurance coverage for OCD patients on leave. ${ }^{6}$
The pathophysiology of OCD has not yet been fully elucidated. It is currently considered a multifactorial disorder (with genetic alterations standing out) associated with neuroimmunological disorders. A literature review ${ }^{7}$ showed agreement on the importance of genetic factors for the expression of OCD, which ranges from $52 \%$ to $80 \%$ in monozygotic twins against $21 \%$ to $25 \%$ in dizygotic twins, contributing to the genetic hypothesis in the pathogenesis of OCD. This hypothesis, which is still under analysis, questions the participation of polygenic modifiers, involved polymorphisms, and linkage mechanisms in serotonergic genes such as HTR2A and 5-HTTLPR, as well as dopaminergic receptor genes such as DRD2 and DRD3. In a systematic review, ${ }^{8}$ autoimmune diseases were related to the outbreak of OCD, in particular group A $\beta$-hemolytic streptococcal infection in children, in addition to systemic lupus erythematosus and thyroid dysfunction in adults. The autoantibodies related to these disorders may cause immunomodulation of cytokines, mainly tumor necrosis factor $\alpha$ and interferons $\gamma$ and $\alpha$, which activate enzymes in the tryptophan cycle, therefore reducing the production of serotonin. ${ }^{7,8}$

The first-line treatment for OCD includes the use of selective serotonin reuptake inhibitors (SSRIs) or tricyclic antidepressants associated with cognitive-behavioral therapy. Nevertheless, this psychiatric disorder has the highest refractoriness to non-invasive treatment (40\% to $60 \%)$. ${ }^{9}$ The symptoms are more prominent in refractory patients, who are characterized by not showing improvement in the condition and presenting with all of the following refractoriness criteria: use of at least three SSRIs at full dose for at least 12 weeks; use of at least two atypical antipsychotics; and combined psychotherapeutic treatment over a period of more than 30 hours. $^{3}$

In the late 1930s, ablative psychosurgeries emerged in the United States for the treatment of psychiatric disorders, especially OCD and major depressive disorder, in patients 
resistant to conventional treatments. ${ }^{10}$ This technique has been improved with the use of a stereotactic approach and imaging tests such as positron emission tomography (PET) and single photon emission computed tomography (SPECT). These advances made the scenario favorable to conduct studies that prove the efficacy and few adverse effects of the procedures, which have already crossed the experimental barrier.

The ablative thermocoagulation technique is based on strong evidence for the involvement of the corticostriatopallidothalamocortical tract in pathophysiological changes, especially the orbitofrontal cortex, anterior cingulate cortex, ventral striatum, anterior limb of the internal capsule, and medial dorsal thalamic nucleus. Postoperative images acquired using a PET/SPECT/computed tomography (CT) scanner were employed to evaluate the metabolism of brain areas, and showed that previous anomalous activities in specific brain circuits improved as a result of the neurosurgery. ${ }^{11}$ Such findings contribute to reiterate the targets recommended in the four main ablative surgeries performed for OCD: anterior capsulotomy, anterior cingulotomy, subcaudal tractotomy, and limbic leucotomy. ${ }^{12}$

In the long run (more than 2 years), $43 \%$ to $75 \%$ of the patients who undergo these procedures show improvements and satisfactory results. ${ }^{10}$ Most adverse effects, such as headache, weight gain, urinary incontinence, cognitive dysfunctions, neurological focal deficits, hemorrhages, and seizures, are transient, lasting from 3 to 6 months. ${ }^{10}$ Permanent and severe adverse effects are restricted to $5.6 \%$ of the cases. ${ }^{3}$ Thus, ablative neurosurgery is an effective and extremely advantageous method for the treatment of refractory OCD, with few adverse effects.

Therefore, the present systematic review aimed to identify validated protocols to observe the effectiveness of ablative neurosurgeries in the treatment of severe and treatment-refractory OCD, their possible adverse effects, and clinical/imagological predictors of response and secondary benefits.

\section{Methods}

A systematic review was performed to investigate the use of ablative neurosurgical techniques for the treatment of refractory OCD. The search was carried out by four independent researchers, and followed the steps proposed in the Preferred Reporting Items for Systematic Reviews and MetaAnalyses (PRISMA) statement.

The search was performed on the Medical Literature, Analysis, and Retrieval System Online (MEDLINE) and on the Coordenação de Aperfeiçoamento de Pessoal de Nível Superior (CAPES, in Portuguese) databases. The following descriptors, retrieved from the Medical Subject Heading (MeSH) terms, were combined in each database using Boolean operators: (obsessive-compulsive disorder or obsessive compulsive disorder) and (ablative or cingulotomy or capsulotomy or tractotomy or leucotomy) and (neurosurgery or psychiatric surgery or neurofunctional surgery).

For the selection of the articles, the following inclusion criteria were adopted: 1 ) studies that correlate refractory OCD and ablative surgery as a treatment strategy, and studies that present OCD treatment using ablative techniques by thermocoagulation and other techniques, as long as the participants who underwent non-ablative surgery can be excluded; 2) human studies that evaluate the efficacy of ablative techniques by thermocoagulation in OCD based on changes in the YaleBrown Obsessive Compulsive Scale (Y-BOCS); 3) individuals diagnosed with OCD according to the Diagnostic and Statistical Manual of Mental Disorders ${ }^{1}$ and the International Statistical Classification of Diseases and Related Health Problems, ${ }^{2}$ and 4) minimum follow-up time of 12 months.

Additionally, the following exclusion criteria were applied: 1) duplicate studies; 2) articles exclusively on other surgical interventions; 3 ) articles exclusively on other psychiatric disorders; 4) editorials; 5) reviews on the use of ablative thermocoagulation techniques for OCD that do not provide results for new patients; 6) comments; 7) discussions on related ethical issues; 8) case reports; 9) studies that do not use the Y-BOCS; and 10) articles on indications for ablative techniques other than OCD.

As a primary outcome, the clinical improvement of OCD symptoms after the intervention, measured by a change in the Y-BOCS score, was analyzed. The secondary outcomes included changes in depression and anxiety scores, and we also retrieved additional information that each article could contribute to the theme. Such secondary outcomes did not affect the eligibility of the studies.

\section{Results}

A total of seven articles were selected for the present systematic review (-Fig. 1, - Table 1). The studies selected included 149 patients, with a mean age at surgery of 34.6 years (range: 28.9 years to 40.8 years; standard deviation [SD]: 4.2 years), who had the diagnosis of OCD following the international criteria, ${ }^{1,2}$ and were considered refractory to the conventional treatment. In four ${ }^{4,13,14,17}$ of the six studies that specified the gender of the patients, males predominated slightly in the sample, while in the two other studies, females represented $66.6 \%^{16}$ and $63.1 \%^{3}$ of the participants. Only one study ${ }^{15}$ comprised two types of surgical procedure and did not specify the gender of the patients. The participants were individualized according to the type of surgery performed, and the number of patients lost to follow-up was reported for each of the types.

Regarding the thermocoagulation techniques performed, 122 patients underwent bilateral anterior capsulotomy; 3, unilateral anterior capsulotomy; 17 , bilateral cingulotomy; and 7, a combination of bilateral anterior capsulotomy and bilateral cingulotomy. After the surgeries, the participants were followed for an average of 25.5 months (range: 12 to 60 months; SD: 15.2 months). The total follow-up time was considered the moment of the last evaluation of the patients.

Clinical improvement was analyzed using the Y-BOCS. The mean preoperative score on the Y-BOCS was of 31.9 (range: 21.2 to 38.2; SD: 5.4). A significant decrease in Y-BOCS scores was observed 12 months after surgery, with a mean value of 16.8 (range: 5.4 to 22.9 ; SD: 6.4 ). The final Y-BOCS score, that is, the one evaluated at the end of the proposed follow-up period, 


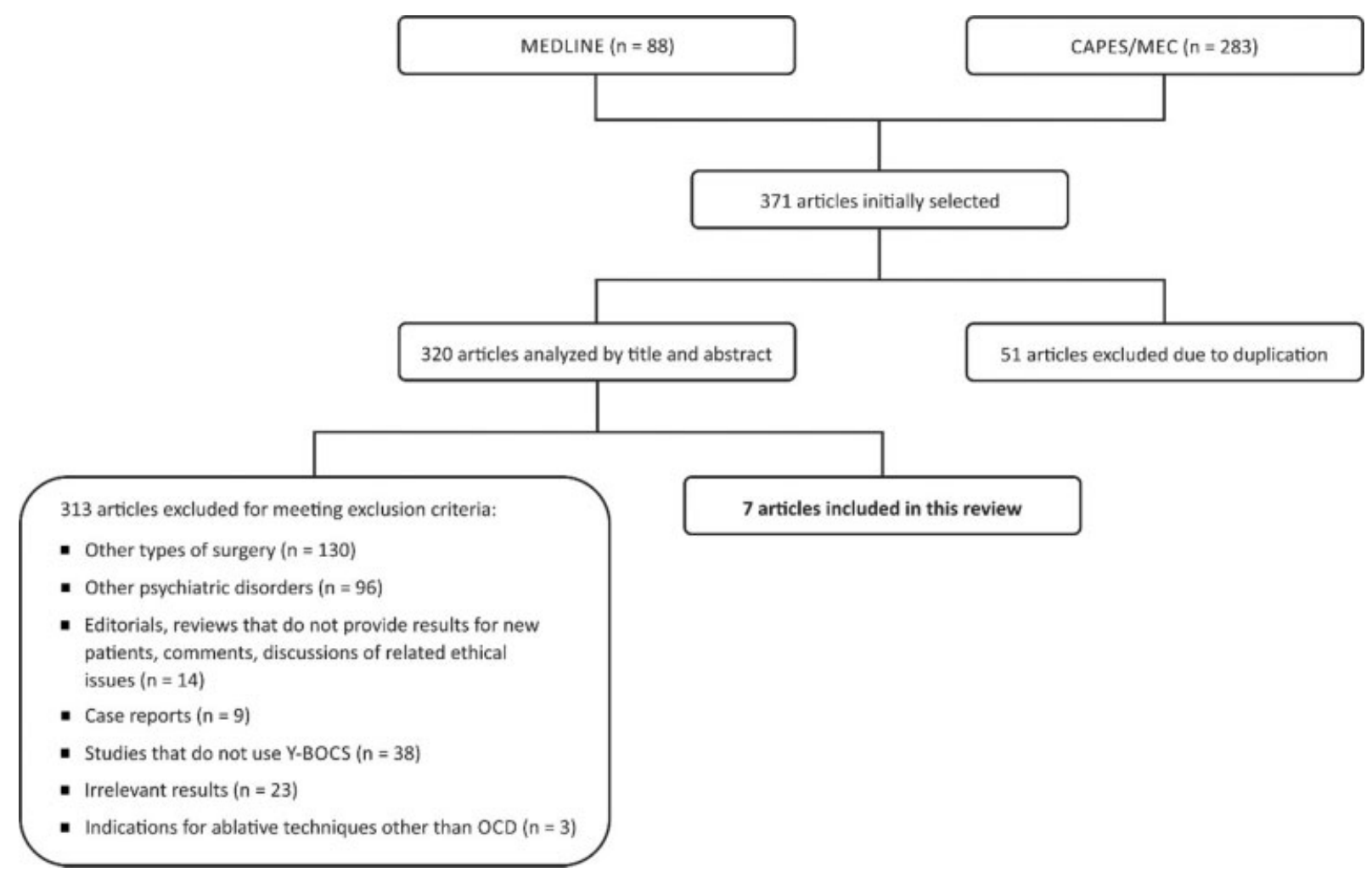

Fig. 1 Articles selected for the systematic review.

continued to decrease, reaching an average of 15.9 (range: 4.4 to 22.9; SD: 6.3 ). This determined an average reduction of $52 \%$ (range: $34.3 \%$ to $79.2 \%$; SD: $15.1 \%$ ) in the Y-BOCS at the end of the evaluation, based on an average of $63.5 \%$ of responders (range: $36.8 \%$ to $85.7 \%$; SD: $15.8 \%$ ). The lowest percentage of responders (36.8\%) and the lowest percentage of decrease in the Y-BOCS score (34.3\%) were found by D'Astous et al. ${ }^{3}$ In contrast, they reported the highest average age among the participants ( 40.8 years). The lowest average ages were registered by Liu et al. ${ }^{14}$ and Zhan et al.: ${ }^{17} 29.6$ years and 28.9 years respectively, while they had the highest rates of responders (85.7\% and $77.3 \%$ respectively).

Csigó et al. ${ }^{16}$ evaluated and implemented neuropsychological tests in their research to assess whether the cognitive functions of OCD patients who underwent ablative neurosurgery improved or worsened after the procedure. They observed a significant recovery of cognitive-functional deficits that refractory OCD patients characteristically have, mainly related to attention and spatial memory. In addition, a significant improvement in executive functions such as verbal fluency, decision making, and intelligence was registered. However, they found an increase in intrusion errors. These findings are corroborated by the results obtained by Jung et al., ${ }^{13}$ who did not identify any neurofunctional deficit in the areas of learning, verbal memory, and visuospatial construction, but observed an improvement in perseveration errors.

Rück et al. ${ }^{15}$ confirmed the efficacy of thermocoagulation in the treatment of refractory $O C D$, but emphasized that multiple or very large lesions should be avoided due to the increased risk of side effects. In turn, Zhang et al. ${ }^{4}$ attributed the response of the participants in their study to the association of bilateral cingulotomy and capsulotomy.

\section{Discussion}

Thermocoagulation for the treatment of refractory OCD is a non-experimental technique that is effective and has been validated by previous studies. This perspective was confirmed in the present review, since the articles selected showed significant clinical improvement documented by changes in the Y-BOCS score. This surgical technique may be the last tool available for these patients to achieve functionality.

In the present review, the average number of responders was of $63.5 \%$, very satisfactory, considering the severity and chronicity of the disease. Mostly, the scores on the Y-BOCS 12 months postoperatively and in the longest follow-up (60 months) were similar. This shows that the 12 -month results are close to the permanent results, and also indicates a stable response to treatment over time.

A greater response to the neurosurgical approach was perceived in younger patients compared with a lower response in older patients, which raises the hypothesis of an ideal time window to propose this approach. Comparing responders and non-responders, D'Astous et al. ${ }^{3}$ concluded that the effectiveness of the surgery is inversely proportional to the duration of the disease. Neuroimaging studies have demonstrated hypermetabolism profiles, especially in the anterior cingulate gyrus, orbitofrontal cortex, and caudate nucleus, areas related to the pathophysiology of OCD which 


\begin{tabular}{|c|c|c|c|c|c|c|c|c|}
\hline $\begin{array}{l}\frac{n}{0} \\
\frac{0}{0} \\
\frac{1}{2}\end{array}$ & 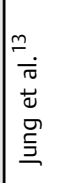 & 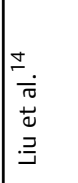 & 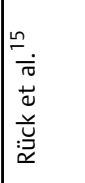 & & 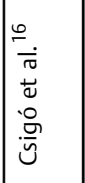 & 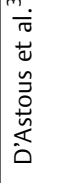 & 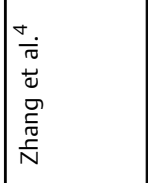 & 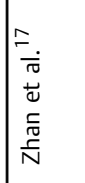 \\
\hline 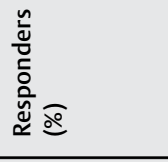 & $\begin{array}{l}\stackrel{\circ}{\dot{F}} \\
\end{array}$ & $\begin{array}{l}0 \\
\infty \\
\infty\end{array}$ & $\begin{array}{l}0 \\
\dot{0} \\
\end{array}$ & $\stackrel{0}{0}$ & $\Sigma$ & $\begin{array}{l}\infty \\
\dot{m} \\
\dot{m}\end{array}$ & $\frac{i}{a}$ & $\stackrel{m}{\stackrel{m}{i}}$ \\
\hline 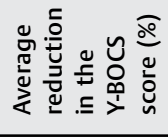 & $\stackrel{\infty}{f}$ & 年 & $\begin{array}{l}\stackrel{n}{\sim} \\
\stackrel{+}{*} \\
\end{array}$ & 字 & $\stackrel{m}{i}$ & $\stackrel{m}{\stackrel{m}{m}}$ & $\mid \stackrel{m}{\stackrel{m}{m}}$ & $\stackrel{0}{i}$ \\
\hline 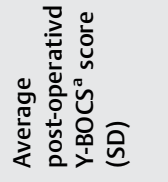 & 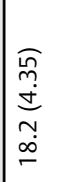 & $\begin{array}{l}\widehat{\tilde{m}} \\
\stackrel{d}{d} \\
\dot{+} \\
\dot{r}\end{array}$ & 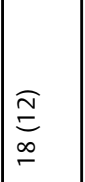 & $\begin{array}{l}0 \\
0 \\
0 \\
9 \\
-\end{array}$ & 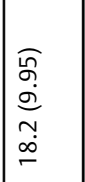 & $\mid \begin{array}{l}\tilde{z} \\
\vdots \\
a \\
\end{array}$ & 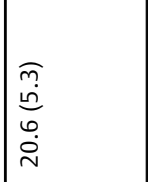 & 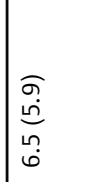 \\
\hline 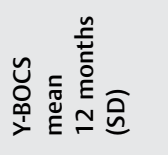 & 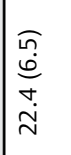 & $\begin{array}{l}\widehat{\widehat{d}} \\
\dot{d} \\
\dot{i n}\end{array}$ & 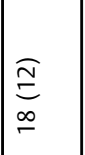 & $\begin{array}{l}0 \\
0 \\
0 \\
0 \\
-\end{array}$ & 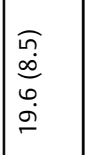 & \begin{tabular}{|l}
$\tilde{z}$ \\
$\vdots$ \\
$a$ \\
$\tilde{N}$
\end{tabular} & 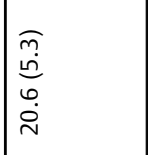 & 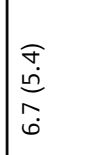 \\
\hline 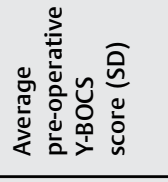 & $\begin{array}{l}\sigma \\
\tilde{n} \\
\omega \\
m \\
m\end{array}$ & 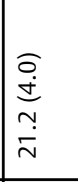 & $\begin{array}{l}\widehat{̃} \\
\stackrel{m}{n} \\
m \\
\dot{m} \\
\end{array}$ & 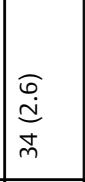 & 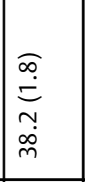 & $\begin{array}{l}a \\
\dot{d} \\
\sigma \\
\sigma \\
\dot{m} \\
\end{array}$ & 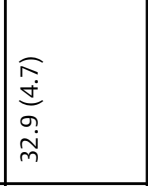 & $\begin{array}{l}\widehat{a} \\
\dot{+} \\
\sim \\
\dot{d} \\
\dot{d}\end{array}$ \\
\hline 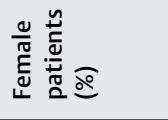 & 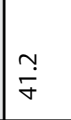 & $\bar{i}$ & $\Sigma$ & 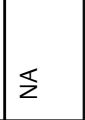 & $\begin{array}{l}\dot{l} \\
\dot{\theta}\end{array}$ & $\overline{\hat{\theta}}$ & \begin{tabular}{|l}
$\infty$ \\
$\dot{F}$ \\
$\dot{F}$
\end{tabular} & $\begin{array}{l}0 \\
\dot{m} \\
\dot{m}\end{array}$ \\
\hline 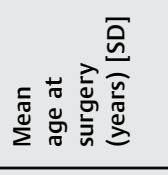 & 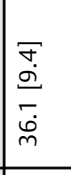 & 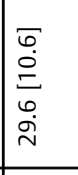 & 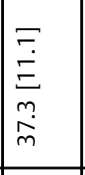 & 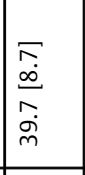 & $\begin{array}{c}\bar{n} \\
\dot{n} \\
\stackrel{\sim}{N} \\
\tilde{m} \\
\end{array}$ & 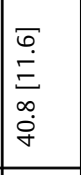 & 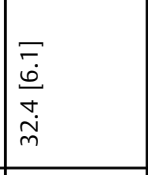 & $\begin{array}{l}\bar{F} \\
\dot{a} \\
a \\
\infty \\
i \\
\end{array}$ \\
\hline 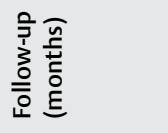 & $\stackrel{\Xi}{\sim}$ & $\stackrel{0}{m}$ & $\simeq$ & $\simeq$ & $\stackrel{\searrow}{\sim}$ & $\stackrel{ \pm}{\sim}$ & $\simeq$ & 8 \\
\hline 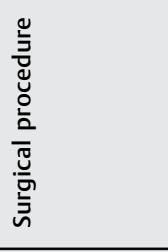 & 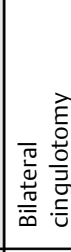 & 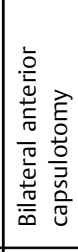 & 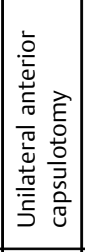 & 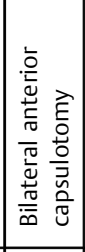 & 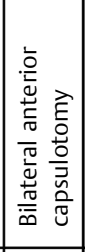 & 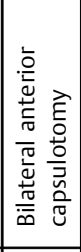 & 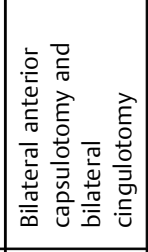 & 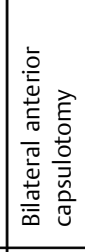 \\
\hline 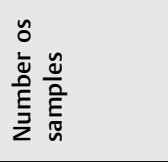 & 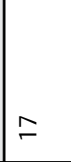 & $\stackrel{\stackrel{n}{m}}{m}$ & in & $\stackrel{\breve{o}}{\circ}$ & in & $\stackrel{9}{\circ}$ & $\curvearrowright$ & $\tilde{n}$ \\
\hline 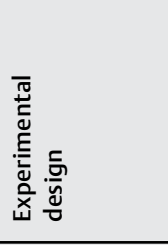 & 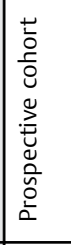 & 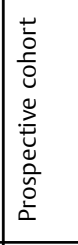 & 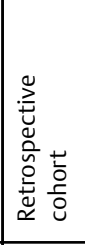 & & 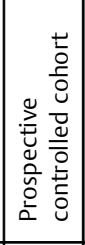 & 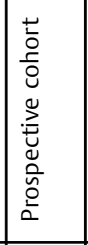 & 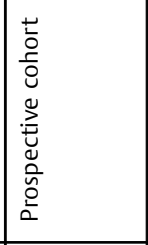 & 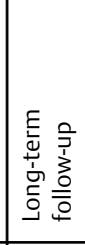 \\
\hline $\begin{array}{l}\vec{E} \\
\text { 音 } \\
\text { U }\end{array}$ & 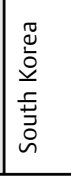 & 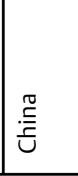 & 离 & & \begin{tabular}{|l} 
裔 \\
空 \\
辛
\end{tabular} & 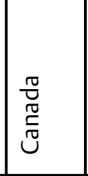 & 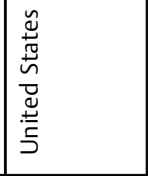 & 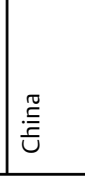 \\
\hline
\end{tabular}


have shown statistically significant improvements in the postoperative follow-up. ${ }^{14,17}$

The comorbidities associated with OCD, such as anxiety and depression, have already been well specified applying the Hamilton Depression Rating Scale (HAM-D) and the Hamilton Anxiety Rating Scale (HAM-A). They have also been analyzed in the postoperative period, showing significant improvement. This fact becomes relevant, considering that these comorbidities have an impact on the quality of life of these patients. ${ }^{12}$ In general, an improvement was also observed in the neurophysiological and cognitive aspects in subjects who underwent this type of surgical treatment, with few long-term adverse effects resulting from the procedure. ${ }^{16}$ However, one study ${ }^{15}$ showed a mild impairment in executive functions in the group studied as a whole.

Despite the reduced number of studies selected, the current systematic review included a significant number of patients (149), and a certain standardization was noticed with regard to the inclusion criteria (every study enrolled refractory patients who had the diagnosis of OCD based on the international criteria), ${ }^{1,2}$ the criterium for responders (patients showing an improvement rate of $>35 \%$ in the YBOCS in the longest follow-up were considered responders), the rating scale (all of them used the Y-BOCS), the total of follow-up time (all of them included a 12-month cutoff), as well as the analysis of secondary outcomes such as depression and anxiety (the studies that performed it used the HAM-A and HAM-D). In addition, the definition of refractory OCD is currently well-established.

The interinstitutional heterogeneity in the surgical technique employed was evident in the studies, such as the amplitude of the lesion and the time and temperature used, even regarding the same type of approach. This fact must be taken into account when generalizing the findings, since this lack of standardization may affect the responses. ${ }^{12}$ Thus, the results of the present systematic review must be interpreted in the context of the strengths and weaknesses of the studies included here.

\section{Conclusion}

Obsessive-compulsive disorder is a debilitating disorder with the highest refractoriness rates among psychiatric disorders. Even with the limited number of studies selected in the present systematic review, the results show that thermocoagulation is a safe and effective method for the regression of the symptoms of this disease. Considering the proportion of responders, both for the primary outcome and for the comorbidities, determining safe clinical predictors of response would be of great value in the application of targeted approaches. Nonetheless, to this date, no evidence is available to determine reliable predictors of imaging studies or the clinical response to the treatment for those patients who are known to have a surgical indication due to severe and refractory OCD. Systematic, double-blinded, controlled studies are feasible (considering the similar response to the different techniques employed) and necessary to overcome this barrier and take a new step toward individualizing surgical indications, especially within the spectrum of those already validated.

\section{Conflict of Interests}

The authors have no conflict of interests to declare.

\section{References}

1 American Psychiatric Association. Diagnostic and statistical manual of mental disorders. 5th ed. Arlington, VA: American Psychiatric Association; 2013

2 World Health Organization. International statistical classification of diseases and related health problems. 10th revision, 5th edition. Geneve: World Health Organization; 2015

3 D'Astous M, Cottin S, Roy M, Picard C, Cantin L. Bilateral stereotactic anterior capsulotomy for obsessive-compulsive disorder: long-term follow-up. J Neurol Neurosurg Psychiatry 2013;84(11): 1208-1213

4 Zhang QJ, Wang WH, Wei XP. Long-term efficacy of stereotactic bilateral anterior cingulotomy and bilateral anterior capsulotomy as a treatment for refractory obsessive-compulsive disorder. Stereotact Funct Neurosurg 2013;91(04):258-261

5 Weissman MM. Cross-national epidemiology of obsessive-compulsive disorder. CNS Spectr 1998;3(S1):6-9

6 Hollander E, Doernberg E, Shavitt R, et al. The cost and impact of compulsivity: A research perspective. Eur Neuropsychopharmacol 2016;26(05):800-809

7 Fernandez-Egea E, Worbe Y, Bernardo M, Robbins TW. Distinct risk factors for obsessive and compulsive symptoms in chronic schizophrenia. Psychol Med 2018;48(16):2668-2675

8 Marazziti D, Mucci F, Fontenelle LF. Immune system and obsessivecompulsive disorder. Psychoneuroendocrinology 2018;93:39-44

9 Pollack MH, Van Ameringen M, Simon NM, et al. A double-blind randomized controlled trial of augmentation and switch strategies for refractory social anxiety disorder. Am J Psychiatry 2014; 171(01):44-53

10 Sharma M, Saleh E, Deogaonkar M, Rezai A. DBS for obsessivecompulsive disorder. In: Sun B, Salles A, editors. Neurosurgical treatments for psychiatric disorders. Dordrecht: Springer Netherlands; 2015:113-123

11 Suetens K, Nuttin B, Gabriëls L, Van Laere K. Differences in metabolic network modulation between capsulotomy and deep-brain stimulation for refractory obsessive-compulsive disorder. J Nucl Med 2014;55(06):951-959

12 Brown LT, Mikell CB, Youngerman BE, Zhang Y, McKhann GM II, Sheth SA. Dorsal anterior cingulotomy and anterior capsulotomy for severe, refractory obsessive-compulsive disorder: a systematic review of observational studies. J Neurosurg 2016;124(01):77-89

13 Jung HH, Kim CH, Chang JH, Park YG, Chung SS, Chang JW. Bilateral anterior cingulotomy for refractory obsessive-compulsive disorder: Long-term follow-up results. Stereotact Funct Neurosurg 2006;84(04):184-189

14 Liu K, Zhang H, Liu C, et al. Stereotactic treatment of refractory obsessive compulsive disorder by bilateral capsulotomy with 3 years follow-up. J Clin Neurosci 2008;15(06):622-629

15 Rück C, Karlsson A, Steele JD, et al. Capsulotomy for obsessivecompulsive disorder: long-term follow-up of 25 patients. Arch Gen Psychiatry 2008;65(08):914-921

16 Csigó K, Harsányi A, Demeter G, Rajkai C, Németh A, Racsmány M. Long-term follow-up of patients with obsessive-compulsive disorder treated by anterior capsulotomy: a neuropsychological study. J Affect Disord 2010;126(1-2):198-205

17 Zhan S, Liu W, Li D, et al. Long-term follow-up of bilateral anterior capsulotomy in patients with refractory obsessive-compulsive disorder. Clin Neurol Neurosurg 2014;119:91-95 